\title{
AÇÕES DO LABORATÓRIO DE LETRAMENTO ACADÊMICO DA UNIVERSIDADE DE SÃO PAULO: PROMOVENDO A ESCRITA ACADÊMICA NA GRADUAÇÃO E NA PÓS-GRADUAÇÃO
}

\author{
Marília Mendes Ferreira* \\ Universidade de São Paulo \\ São Paulo, São Paulo, BR \\ Eliane Gouvêa Lousada ${ }^{* *}$ \\ Universidade de São Paulo \\ São Paulo, São Paulo, BR
}

\begin{abstract}
Resumo
A internacionalização crescente das universidades brasileiras (MOROSINI, 2011; SILVA; LOUSADA,2014) impõe para a comunidade acadêmica do país novas demandas linguísticas, não somente leitura, mas também a comunicação efetiva de forma oral e escrita no discurso acadêmico em pelo menos duas línguas - a materna e a estrangeira (sobretudo o inglês). Entretanto, condições materiais para o atendimento dessas demandas são praticamente inexistentes nas instituições de ensino superior brasileiras (FERREIRA, 2015). O objetivo deste artigo é expor um projeto em andamento, ou seja, uma ação que visa atender a uma dessas demandas impostas pela internacionalização - a socialização por meio da escrita acadêmica em inglês, francês e português, não somente para fins de leitura e assimilação de conteúdo, mas sobretudo para a publicação nessas línguas. Essa ação é empreendida pelo Laboratório de Letramento Acadêmico da Universidade de São Paulo.

Palavras-chave: Laboratório de Letramento Acadêmico; Letramento Acadêmico; Escrita Acadêmica; Internacionalização.
\end{abstract}

\section{ACTIONS OF THE ACADEMIC LITERACY LABORATORY OF THE UNIVERSITY OF SÃO PAULO: PROMOTING ACADEMIC WRITING IN THE UNDERGRADUATE AND GRADUATE PROGRAMS}

\begin{abstract}
The increasing internationalization of Brazilian universities requires its academic community not only to read, but also to communicate effectively in academic discourse in at least two languages - the mother tongue and a foreign language (mainly English). However, material conditions for meeting these demands are practically nonexistent in Brazilian higher education institutions (FERREIRA, 2015). The purpose of this article is to describe an action that aims to meet one of these demands imposed by internationalization - the socialization of academic production in English, French and Portuguese not only for reading purposes and assimilation of content, but above all for publication in these languages. This action is undertaken by the Academic Literacy Laboratory at the University of São Paulo.
\end{abstract}

Keywords: Academic Literacy Laboratory; Academic Literacy; Academic Writing; Internationalization.

\footnotetext{
* Possui graduação em licenciatura port-inglês e literaturas pela Universidade Federal de Uberlândia (1995), mestrado em Linguística Aplicada pela Universidade Estadual de Campinas (2000) e doutorado em Linguística Aplicada - The Penn State University (2005). Atualmente é professora do Departamento de Letras Modernas da Faculdade de Filosofia, Letras e Ciências Humanas, na Universidade de São Paulo. Seus interesses de pesquisa envolvem aspectos do ensino e da aprendizagem de línguas estrangeiras sob a ótica sócio-histórico cultural e da teoria da atividade de segunda e terceira gerações. Seu endereço de email é mmferreira@usp.br

** Possui mestrado (1998) e doutorado (2006) em Linguística Aplicada e Estudos da Linguagem pela Pontifícia Universidade Católica de São Paulo. Atualmente é professora do Departamento de Letras Modernas da Faculdade de Filosofia, Letras e Ciências Humanas, na Universidade de São Paulo. Tem experiência nas áreas de desenvolvimento e formação de professores, elaboração de material didático baseado na noção de gênero textual e análise de textos e discursos, com publicações científicas nessas áreas. Seu endereço de email é elousada@usp.br
} 


\section{Introdução}

O processo de internacionalização crescente das instituições de ensino de nível superior brasileiras impõe para a comunidade acadêmica do país novas demandas linguísticas. Não basta mais ler em uma língua que pouco se dominava, mas sim se comunicar de forma oral e escrita no discurso acadêmico em pelo menos duas línguas: a materna e a estrangeira (sobretudo o inglês). De fato, a internacionalização das Instituições de Ensino Superior brasileiras traz consequências para o ensino em nível superior e para a pesquisa, que implicam a) por um lado, aprender a produzir gêneros textuais que circulam, na esfera universitária, para realizar uma parte de seus estudos em um país de língua estrangeira cuja língua difere de sua língua materna; b) por outro lado, aprender a produzir gêneros textuais que circulam, na esfera acadêmica, em uma língua que permita a apresentação de trabalhos, publicações e participação em grupos de pesquisa internacionais. No primeiro caso (a), a língua na qual os textos devem ser produzidos é a língua do país em que se realiza o intercâmbio. No segundo caso (b), a língua pode ser o inglês, enquanto língua que permite o diálogo entre pesquisadores juniores ou seniores de diferentes países, mas também pode ser uma outra língua, falada pela maioria dos pesquisadores ou, ainda, escolhida como língua de comunicação no lugar do inglês. Tal é o ponto de vista de Gajo (2013, p. 97) ao nos lembrar "o papel central do discurso, que serve não apenas para transmitir saberes, mas para elaborá-los". ${ }^{1}$ Nessa linha de raciocínio, a língua utilizada para a pesquisa científica e para a produção textual que circula na esfera acadêmica/ universitária constitui o próprio saber que é elaborado.

Esse contexto, portanto, leva a um repensar do ensino da escrita nessas línguas. No Brasil, tradicionalmente, o ensino da escrita acadêmica em português é quase inexistente. A sua presença poderia ser mais constante na graduação de Letras com cursos como produção textual ou de leitura e produção textual ou mesmo de metodologia científica. Em outras áreas, a depender da sua iniciativa, pode-se também inserir essas disciplinas. Quer seja na graduação em Letras ou em outras áreas, pode-se encontrar um ensino isolado da habilidade escrita, desvinculado das disciplinas do currículo.

$\mathrm{O}$ caso do curso de Letras é bem ilustrativo. $\mathrm{Na}$ graduação, o aluno tem contato com duas disciplinas que não compartilham o mesmo modo de escrever: linguística e literatura. Dessa forma, essas ações são de caráter isolado, não constituindo uma política de ensino da escrita acadêmica. Além disso, os alunos frequentemente ingressam na graduação com uma experiência de escrita restrita a gêneros textuais relacionados a provas padronizadas para avaliação do sistema de ensino e vestibulares e, como consequência, não estão socializados com as especificidades do discurso acadêmico.

Especificamente no caso da língua estrangeira, com as crescentes oportunidades de mobilidade dos universitários brasileiros para fora do país, oriundas da internacionalização, exige-se dos alunos de graduação e pós-graduação que escrevam adequadamente na língua em questão e em gêneros textuais que, muitas vezes, não são exigidos no contexto brasileiro (SILVA; LOUSADA, 2014). Para recrudescer a situação, a escrita não é uma habilidade alvo nos cursos livres de idiomas, local tradicional e de prestígio na sociedade brasileira para a aprendizagem da língua estrangeira (FERREIRA, 2011). Como consequência, o aluno chega à universidade também sem uma noção clara do que seja o discurso acadêmico em língua estrangeira.

Tanto no ensino da escrita em português quanto em língua estrangeira, a abordagem generalista de ensino da escrita é adotada como pressuposto. Nessa perspectiva, a escrita é vista sobretudo como habilidade (STREET, 1984) desenvolvida de modo descontextualizado e, por isso, pode ser utilizada em diferentes contextos. Dessa forma, ensinar a escrita nos ensinos fundamental e médio consiste em ensinar habilidades que serão utilizadas na esfera acadêmica. Como a escrita não é vista como prática social (STREET, 1984), a escrita da esfera escolar é igualada à escrita na esfera acadêmica. Com essa crença, é fácil acreditar que as dificuldades do aluno com a escrita na universidade ocorrem devido a uma escrita problemática na escola regular.

Já numa visão especifista (HYLAND, 2002), o letramento está intimamente ligado a práticas sociais específicas e não pode unicamente se basear em habilida- 
des transferíveis. O desenvolvimento da linguística de corpus e da análise de gêneros textuais permitiu uma análise mais detalhada do comportamento linguístico em textos de diferentes disciplinas levando à identificação da especificidade do discurso em diferentes disciplinas. Essa abordagem conduz a um compartilhamento da responsabilidade do letramento acadêmico: não somente do professor de língua, mas também de professores, membros da comunidade discursiva do aluno (FERREIRA, 2015).

Conforme nos alertam Ferreira e Rios (em preparação), há sérias implicações, sob os pontos de vista pedagógico e administrativo, na adoção dessas posturas, seja de forma consciente ou não. A abordagem generalista permite à universidade se eximir da responsabilidade pelo letramento (ela fica a cargo da escola regular) e, caso a adote, pode representar menor custo financeiro. Já a especifista coloca em cena o membro da comunidade discursiva que pode ofuscar o trabalho do profissional da linguagem. Além disso, do ponto de vista administrativo, a adoção da perspectiva especifista pode não ser vantajosa, pois implica o envolvimento no processo de pelo menos dois profissionais: o de língua e o especialista na área.

Acreditamos que é crucial pensar sobre essas duas abordagens e seus pressupostos, pois elas afetam o delineamento de políticas de promoção e ensino do letramento (leitura e escrita) na academia. Uma pergunta que não se pode mais evitar, diante da necessidade urgente do letramento acadêmico para a comunidade acadêmica brasileira, é a seguinte: de quem é a responsabilidade desse letramento, assumindo que ele não é geral e sim específico a práticas sociais? Seria dos professores de português, de línguas estrangeiras? Dos professores de disciplinas da área do aluno? De um professor nativo que está na área do aluno? Do orientador? De um writing center ${ }^{2}$ ? Do aluno? De todos? Ou de alguns e em que relação? Essas perguntas precisam ser respondidas para se delinear políticas adequadas para o letramento acadêmico.

O cenário atual descrito acima, portanto, é composto por uma grande contradição em que as demandas linguísticas impostas pela internacionalização, apesar de crescentes, não parecem estar claras para alunos, docen- tes e gestores. Talvez, por isso, condições materiais para sua promoção são praticamente inexistentes nas instituições de ensino superior brasileiras (FERREIRA, 2015). Um exemplo dessa contradição pode ser encontrado na ausência de locais de assistência à escrita para a publicação, em português ou em línguas estrangeiras, nas universidades brasileiras. Baseada em um breve levantamento nos sites das principais universidades brasileiras, Ferreira (2015) encontra pouquíssimas iniciativas e de forma isolada: 1) oficinas de editoras internacionais que inserem, na sua programação, dicas para a escrita em inglês com foco na publicação como atrativo para suas ações de captação de novos autores (Springer, Elsevier, por exemplo), 2) serviços terceirizados para tradução de textos do português para algumas línguas estrangeiras e revisão de textos em português, ${ }^{3}$ que constituem uma ação paliativa, pois não ensina o pesquisador ou futuro pesquisador a escrever na língua alvo. ${ }^{4}$

O objetivo deste artigo é descrever uma ação que visa atender a uma dessas demandas impostas pela internacionalização: a socialização da produção acadêmica por meio da escrita acadêmica em inglês e francês, não somente para fins de leitura e assimilação de conteúdo, mas, sobretudo, para a publicação nessas línguas. As ações voltadas ao português, embora não sejam detalhadas neste artigo por falta de espaço, constituem também um foco prioritário do Laboratório. Essa ação é empreendida pelo Laboratório de Letramento Acadêmico da USP, ${ }^{5}$ fundado em 2011. Vale destacar que, no Brasil, pelo que sabemos, há apenas uma outra iniciativa semelhante na Universidade Federal de Santa Maria. ${ }^{6}$

$\mathrm{O}$ artigo está organizado da seguinte forma: exposição do conceito de letramento adotado por nós, o contexto de sua criação na USP, os objetivos do Laboratório, a descrição de suas ações, seus planos futuros e desafios enfrentados.

\section{A visão de letramento acadêmico adotado pelo Laboratório}

O conceito de letramento acadêmico pode ser abordado sob três aspectos, segundo Ferreira, (2015): 1) generalidade e especificidade (HYLAND, 2002), 2) foco de investigação ou na forma ou no contexto social, 
3) habilidade autônoma ou prática social afetada pela ideologia (STREET,1984). Na introdução deste artigo, expusemos as visões generalista e especifista. Ferreira (2015) compara o foco na forma e no social pelos estudos do letramento. $\mathrm{O}$ foco na forma significa considerar o estudo do letramento concentrado em unidades formais: construções formulaicas, aspectos lexicais e gramaticais do texto no caso da linguística de corpus e movimentos e passos, no caso da análise de gênero numa visão sócio-retórica (Swales, 2004). Com essa descrição formal, objetiva-se socializar o aluno, muitas vezes desprovido de uma visão crítica, no uso acadêmico da linguagem. Já o foco no social busca discutir e descrever os aspectos sociais dessas práticas de letramento em detrimento da forma (ver, por exemplo, CANAGARAJAH, 2002; FREEDMAN e MEDWAY,1994; LEA e STREET, 1998; LILLIS E CURRY, 2010; MILLER, 1984). Deve-se esclarecer que tanto Street (1984) quanto Hyland (2002) adotam uma visão especifista do letramento, mas de formas diversas. Enquanto o primeiro situa a especificidade do letramento na prática social que o constitui, o segundo o situa na descrição formal do discurso utilizado por determinada comunidade discursiva.

Ferreira (2015) chama a atenção para um aspecto do letramento: a influência capitalista no fenômeno. Baseada em Brandt (2002), ela reporta como o letramento deixou de ser um bem público, promotor da cidadania, para se tornar uma commodity, "um produto privado, uma habilidade alugável, cuja propriedade, o controle e a padronização são reservados somente para alguns e cujo acesso é controlado por alguns setores da sociedade" (FERREIRA, 2015, p.18)

Diante dessa complexidade que o termo letramento acadêmico representa, adotamos a seguinte visão de letramento:

[...] a socialização crítica do uso da língua na academia para ler, escrever ou falar textos que visam a produção, a disseminação e a sustentação da produção do conhecimento acadêmico segundo as convenções linguísticas, genéricas e sociais das comunidades discursivas e que se baseiam em habilidades gerais do letramento. Essa socialização crítica visa conduzir os in- gressantes a um estágio de negociação dessas convenções com a comunidade discursiva ou mesmo serem agentes de criação das mesmas. Pode-se observar que a definição busca abarcar as visões generalista como base de construção de uma visão específica e almeja contemplar tanto os aspectos formais quanto sociais numa visão crítica de socialização. As habilidades gerais necessárias para o letramento acadêmico seriam expor, argumentar, resumir, buscar, hierarquizar e relacionar informações, valorizar raciocínios, debater (CARLINO, 2013), ter consciência retórica das regras da comunidade discursiva (HYLAND, 2002, 2009; SWALES e FEAK, 2004), persuadir sobre a validade dos argumentos, negociar conhecimento, valores (HEWINGS, 2001). Por essa lista de habilidades pode-se perceber a importância do letramento acadêmico e como seu trabalho pode ser facilitado com o letramento ocorrido na escola regular. (FERREIRA, 2015, p.18-19)

Pode-se notar, pela definição, que buscamos investigar o letramento sob os seus vários aspectos (formais, sociais, ideológicos), em vez de abordá-lo somente por uma perspectiva teórica particular. Acreditamos que a compreensão multifacetada do letramento nos possibilitará o delineamento de ações pedagógicas e criação (ou, pelo menos, sugestões) de políticas para sua promoção de forma mais efetiva na universidade.

No que diz respeito ao conceito de gênero, partimos da definição bastante consensual de Bakhtin (1997/1953, p. 279): “[...] cada esfera de utilização da língua elabora seus tipos relativamente estáveis de enunciados, sendo isso que denominamos gêneros do discurso" e de seus desdobramentos e adaptações para outras linhas teóricas, que consideram os gêneros como: unidades comunicativas globais que contribuem para os processos de socialização (BRONCKART, 1999); codificadores dos traços característicos das estruturas e eventos sociais, como aponta Balocco (2005, p. 65); formas de ação social que constituem um repertório de formas discursivas, ações e motivos, para Bazerman (2007, p. 22); ou, ainda, para Swales (1990, p.58) "uma classe de eventos comunicativos, cujos membros compartilham um conjunto de objetivos comunicativos".7 Esses objetivos são reconhecidos pelos membros da comunidade discursiva e, portanto, constituem a base do gênero textual. 
De qualquer forma, as definições acima ressaltam o caráter fortemente social dos gêneros como organizadores discursivos da ação linguageira. Sendo assim, da mesma maneira que, para a definição de letramento, acreditamos que compreender o que são gêneros textuais/discursivos a partir de diferentes perspectivas teóricas contribui para uma reflexão mais ampla sobre as questões práticas que envolvem a produção textual e facilita tanto a implementação de práticas pedagógicas quanto a promoção de políticas plurilíngues de produção do conhecimento na universidade.

\section{Contexto de criação do Laboratório}

O Laboratório de Letramento Acadêmico em Línguas Materna e Estrangeiras foi criado em 2011 e passou a funcionar efetivamente a partir do segundo semestre de 2012 como submissão a um Edital da USP para a criação de novos laboratórios e apoio aos já existentes. A grande motivação para tal iniciativa se deveu à constatação das professoras envolvidas da necessidade, cada vez mais urgente, da universidade de preparar os alunos para novos contextos de comunicação na qual a língua materna e a estrangeira convivem e o registro escrito é fundamental para a divulgação do conhecimento acadêmico.

O tratamento da USP para o letramento acadêmico se assemelha ao de outras universidades brasileiras. Por um lado, as disciplinas da graduação e da pós dos diversos cursos da USP não dispõem de tempo para o ensino da escrita, seja em língua materna, seja na língua estrangeira. Os alunos frequentemente ingressam na USP com uma experiência de escrita restrita a gêneros relacionados a provas padronizadas para avaliação do sistema de ensino e vestibulares e praticamente inexiste uma socialização com as especificidades do discurso acadêmico. $O$ ingresso na pós-graduação se pauta por exames cujo aferimento do conhecimento da língua estrangeira muito frequentemente se limita à leitura de textos. Por outro lado, com a internacionalização e as crescentes oportunidades de intercâmbio com instituições estrangeiras para a graduação e a pós, a necessidade de se escrever adequadamente na língua estrangeira se impõe tornando o letramento e, sobretudo a escrita, uma commodity com alto valor agregado (BRANDT, 2002; JUZWIK, 2006; WARSCHAUER, 2000) tanto para a academia quanto para o exercício das profissões. Portanto, a escrita tornou-se um capital cultural (BOURDIEU,1986) e o domínio da língua estrangeira vai além da leitura instrumental de textos (VASCONCELOS, SORENSON, LETA, 2007).

O aluno, sem apoio de livros ou manuais nas bibliotecas, de tutores que o auxiliem nesse processo, recorre ou à tradução, como medida emergencial, ou ao orientador, para auxílio imediato caso esse(a) se disponha a orientá-lo nesse letramento. Em ambos os casos, o ensino do letramento não ocorre de forma efetiva. Deve-se ter em mente que o discurso acadêmico é difícil de ser aprendido tanto em língua materna quanto em língua estrangeira (CASANAVE, 1995; CHARLES, PECORARI, HUNSTON, 2009).

A promoção do letramento acadêmico requer condições materiais mais adequadas para sua promoção (MOTTA-ROTH, 2009; SALAGER-MEYER,2008; VASCONCELOS, SORENSON, LETA, 2007; UZUNER, 2008) - parcas como vimos pela descrição acima no Brasil - e um nível apropriado de proficiência linguística. A cienciometria nos revela uma forte correlação estatística entre proficiência linguística e publicação, ou seja, quanto maior o nível de proficiência linguística do pesquisador mais ele publica em inglês. Essa variável é mais influente do que o investimento em pesquisa (MAN et al., 2004). Vasconcelos, Sorenson e Leta (2007) confirmam essa correlação para o contexto brasileiro e verificam que a maioria de seus pesquisadores lê muito melhor do que escreve, o que é fruto do projeto do inglês instrumental implementado no país desde a década de 1980.

Como se pode observar, o letramento acadêmico é uma necessidade urgente da academia brasileira que requer ações efetivas. O Laboratório consiste numa ação da Universidade de São Paulo nesse sentido. A seguir, veremos seus objetivos, funcionamento e as ações que promove.

\section{Objetivos do Laboratório}

Os objetivos do Laboratório são os seguintes : a) criar uma infraestrutura física e com material humano qualifi- 
cado para o ensino sistematizado da redação acadêmica tanto em língua materna quanto estrangeira no curso de Letras $^{8}$ e em outras unidades da USP interessadas; $b$ ) oferecer tutorias de escrita acadêmica nessas línguas para discussão e consequente aperfeiçoamento de seus textos em seus diversos aspectos (macroestruturais, retóricos, linguísticos, estilísticos etc.) ; c) oferecer oficinas sobre habilidades específicas do letramento acadêmico como paráfrase, resumo, citação e sobre aspectos pontuais como plágio, características do discurso acadêmico, retórica contrastiva, metadiscurso, público-alvo, além de outras focadas em alguns gêneros específicos (o resumo, por exemplo) ; d) proporcionar formação profissional ao monitor em relação ao ensino da escrita acadêmica e na correção de textos em diversos níveis (e não somente no nível gramatical e vocabular) enriquecendo, assim, sua formação pedagógica; e) constituir-se num espaço de estudo, reflexão e teorização sobre o ensino do letramento em línguas materna e estrangeira e de descrição do discurso acadêmico em diferentes áreas do conhecimento para oferecer suporte teórico às tutorias. Essas ações são realizadas a partir de diferentes perspectivas teóricas promovendo o debate e a pluralidade de linhas teóricas entre os membros da equipe do Laboratório ; f) oferecer cursos de capacitação a professores da rede regular de ensino para o trabalho com a escrita; g) oferecer consultorias sobre formas de promoção do letramento acadêmico a docentes de diferentes áreas do saber.

Como se pode notar, a proposta do Laboratório, em certa medida, se assemelha ao Writing Center tão presente em universidades americanas, canadenses e europeias. Enquanto o writing center se caracteriza fundamentalmente como um centro de prestação de serviço e com objetivo de desenvolver a escrita no aluno (ROCCO et al, 2015; LOUSADA e GUIMARÃES-SANTOS, no prelo), o Laboratório se configura como um centro de estudos do letramento acadêmico sob diversas perspectivas e que busca conciliar pesquisa e extensão (oferecendo também serviço à comunidade da USP). As atividades de extensão se concretizam por meio de tutorias individuais, oficinas, palestras e consultorias.

Antes de passarmos à descrição dessas ações, na próxima seção, parece-nos importante esclarecer a escolha da palavra Laboratório. Utilizamos duas acepções da palavra como definida pelo dicionário Michaelis da língua portuguesa: 1) lugar de trabalho e investigação científica, 2) lugar de grandes operações ou de transformações notáveis. Cremos que essa palavra expressa o que objetivamos com o Laboratório: investigar sob vários aspectos e correntes teóricas o letramento acadêmico e promover mudanças na academia em relação a esse tema por meio da criação de material didático, consultorias, mudança de valores e atitudes em relação ao letramento e, sobretudo, da prática pedagógica em relação ao ensino do letramento acadêmico. A escolha do termo Laboratório enfatiza o fato de se tratar não apenas de um prestador de serviços, como no caso das universidades do exterior, mas como um local de experimentação e, portanto, de pesquisas sobre a escrita acadêmica e seu ensino.

\section{Ações do Laboratório}

Nesta seção, descrevemos as principais ações do Laboratório, que vão desde tutorias aos alunos até consultorias, passando por cursos de formação, palestras e oficinas.

\subsection{Tutorias de escrita acadêmica e trein- amento de tutores}

São tutorias individuais para auxiliar a comunidade acadêmica (discentes e docentes) a escreverem no discurso acadêmico em inglês, francês e português. As sessões, com duração de 20 a 30 minutos, conduzidas pelo tutor, tratam de aspectos diversos do texto com o seu autor: linguísticos, genéricos, retóricos, estruturais. Esse procedimento, advindo da abordagem processual do ensino da escrita e denominado de conferência, busca oferecer ao autor a visão de uma terceira pessoa sobre seu texto. Independente da proficiência do autor no idioma ou de sua habilidade com a escrita, as conferências são úteis pois oferecem esse terceiro olhar sobre o texto. O objetivo também é auxiliar o autor a identificar suas dificuldades com a escrita e oferecer apoio pedagógico para sanar essas dificuldades.

O treinamento dos monitores é constante e ocorre por meio de sessões de treinamento com leituras e atividades práticas de revisão e correção de textos sob 
vários aspectos e por meio de encontros dos monitores e coordenadores para discutir questões pontuais da prática de tutoria. A postura diante do texto alheio, características linguísticas do texto acadêmico em francês, inglês, português, conceitos de gênero textual e as diversas escolas, abordagens do ensino da escrita são alguns dos temas abordados.

Para auxiliar a tutoria, alguns procedimentos foram adotados, como, por exemplo, fichas a serem preenchidas pelos monitores e pelos discentes e/ou docentes que procuram o Laboratório. As fichas procuram, por um lado, conhecer melhor o público que frequenta o Laboratório, identificando suas necessidades, verificando se o atendimento cumpriu seus objetivos etc.; e, por outro lado, visam a arquivar informações importantes que servirão para a pesquisa que é desenvolvida nesse contexto. Algumas fichas podem ser consultadas nos anexos (01 e 02) deste artigo.

Outra ação importante ligada à tutoria é a parceria com disciplinas da graduação e da pós-graduação. $\mathrm{Na}$ área de Francês, podemos mencionar dois exemplos:

- em uma disciplina obrigatória da graduação em Francês (Monografia - oferecida anualmente), foi estabelecida uma parceria que começou em 2013 e se repetiu em 2014 e 2015. Por meio da parceria, uma monitora do Laboratório trabalhou juntamente com a professora do curso para: oferecer aos alunos três aulas em que eles aprendiam a escrever um artigo científico, da área de literatura, como produção textual monográfica exigida ao término do curso; oferecer atendimento no Laboratório para auxiliá-los na escrita final do artigo. Nesse caso, a tutoria do Laboratório era opcional.

- nas disciplinas obrigatórias Francês 1 e 2, os monitores acompanharam a escrita dos textos que deveriam ser redigidos para cada uma delas, a saber: diário de leitura, para Francês 1 e resumo, para Francês 2. Nesse caso, a tutoria era obrigatória, sendo que os alunos tinham seus pontos validados pela presença, ao menos uma vez, aos atendimentos do Laboratório.
$\mathrm{Na}$ área do Inglês, essa parceria ocorreu nas seguintes disciplinas de graduação (habilitação em Letras Inglês): Escrita Acadêmica em Inglês, Expressão Escrita em Inglês e Introdução ao Conto. Essa colaboração permitiu que, nas sessões individuais, vários aspectos dos textos produzidos pelos alunos fossem discutidos e uma maior conscientização de suas dificuldades na escrita fosse promovida. Além disso, focamos também na oferta de recursos aos alunos para melhorarem sua escrita, como o uso de dicionários monolíngues disponíveis na internet, a adequação do texto a uma audiência específica, a intepretação das instruções dos professores para a tarefa escrita, ensino do gênero textual pedido pelo professor na tarefa. Nas disciplinas de escrita, o atendimento era obrigatório, com nota prevista na avaliação. Na disciplina de literatura, a professora responsável optou por encaminhar os alunos com mais dificuldades no idioma.

Vale ressaltar que o sucesso dessas parcerias depende em grande medida do comprometimento dos professores da disciplina com a ação do Laboratório e da conscientização dos mesmos da importância desse novo (para o contexto brasileiro) recurso pedagógico para o ensino e promoção da escrita no curso em questão. Se eles consideram que este pode ajudá-los quanto à qualidade da produção textual de seus alunos, o apoio à visita ao Laboratório é valorizado e os alunos tendem a participar mais dos atendimentos. Dessa forma, faz-se crucial um trabalho constante com os professores das disciplinas para colaborarem com o Laboratório não somente por meio do encaminhamento dos alunos de forma opcional ou por nota, mas também nos auxiliando na difícil tarefa de introduzir, na rotina, um novo artefato cultural, no sentido vygotskiano (VYGOTSKY, 1997): a utilização frequente do Laboratório como mediação para aprimoramento de seu texto e para a aprendizagem da escrita.

Ao longo dos quatro anos de funcionamento do Laboratório, a parceria com disciplinas se tornou uma maneira eficaz de dar visibilidade às ações que desenvolvemos, divulgar o trabalho dos monitores e, sobretudo, auxiliar os alunos concretamente nos trabalhos que têm que realizar para as diferentes disciplinas da graduação e da pós-graduação. 


\subsection{Palestras e oficinas}

As palestras e oficinas são ofertadas ou por convidados ou pela própria equipe do Laboratório e versam sobre temas do letramento acadêmico e baseados em pesquisas conduzidas por seus apresentadores. Abertas ao público em geral, ambas contribuem para divulgar o Laboratório e atuar na formação dos discentes e docentes para o letramento acadêmico.

Os seguintes temas já foram abordados: o plágio na academia; o papel da escrita no desenvolvimento da ciência; aspectos coesivos em resumos de textos e interatividade em resumos (abstracts); gêneros resumo para congresso e apresentação oral; tecnologias digitais e escrita na universidade.

\subsection{Consultorias}

As consultorias consistem em ações para promover o ensino do letramento acadêmico nos diversos institutos da USP. O objetivo é conscientizar a comunidade acadêmica de que o letramento não ocorre somente ou, principalmente, em iniciativas isoladas como oficinas de editoras internacionais, cursos de escrita pontuais ou oficinas com temas sobre o letramento. Apesar de iniciativas louváveis que visam sanar dificuldades históricas do Brasil com a escrita e enfrentar um novo desafio - a escrita acadêmica em inglês para a publicação -, elas são uma ação emergencial e paliativa. Com essa constatação, buscamos trabalhar com professores e coordenadores de pósgraduação para conscientizá-los de sua responsabilidade para a promoção do letramento acadêmico e delinear ações conjuntas que o promovam na sua própria disciplina (BAZERMAN et al., 2005; RUSSELL, 2002). É importante conscientizar a academia que leitura e escrita caminham juntas e que, para se aprender a escrever, é preciso também exigir isso dos discentes enquanto cursam disciplinas. A escrita pode ser aprendida de forma sistemática, com feedback apropriado, num processo rico em vez de ser simplesmente exigida dos alunos e desacompanhada de adequado apoio material e por meio de gêneros bastante arriscados como resumos e artigos acadêmicos.
O Laboratório também oferece consultorias pontuais a setores da Universidade de São Paulo sobre demandas de proficiência em inglês da comunidade. Por exemplo, podemos citar a avaliação de Massive Open Online Courses ${ }^{9}$ de escrita acadêmica em inglês realizada para posterior apoio da Universidade a essa iniciativa.

\subsection{Cursos de extensão}

Como iniciativa do Laboratório, temos proposto tanto cursos para auxiliar alunos, quanto cursos de formação de professores, como apresentamos a seguir.

5.4.1. Cursos sobre produção textual de gêneros acadêmicos

No caso do Francês, temos oferecido desde 2015 um curso de extensão sobre gêneros acadêmicos voltado para o público universitário (tanto alunos de graduação quanto de pós-graduação, com nível de francês mínimo B1), no intuito de preparar os alunos para a produção textual acadêmica em francês. Nesse curso, intitulado "Gêneros textuais acadêmicos: produção de textos orais e escritos em francês para participação no contexto universitário", e que já foi oferecido em três edições diferentes, são trabalhados os gêneros: resumo, resenha, resumo para congressos, apresentação oral e artigo científico, sendo que os dois primeiros são obrigatórios, mas os outros são escolhidos pelos alunos em função de suas necessidades. Para ministrá-lo, o material didático foi inteiramente elaborado a partir de textos autênticos pertencentes aos gêneros escolhidos e foram trabalhados aspectos contextuais, discursivos e linguísticos relacionados aos gêneros em questão. Em cada edição do curso, o material foi modificado visando atender ao público tanto no que diz respeito ao que os alunos deveriam produzir na universidade brasileira, em francês, quanto aos gêneros que deveriam produzir para participar em um contexto internacional, seja para apresentação de suas pesquisas em contexto francófono ou para realização de estudos em uma universidade francófona.

O curso alcançou um alto índice de satisfação, pois, ao contrário de outros cursos que focam na escrita acadêmica em geral, independentemente do gênero 
textual que se tem que produzir, nosso curso abordou os gêneros textuais de interesse para os alunos e suas especificidades, que podem diferir entre si. Além disso, o curso não focalizou apenas características linguísticas, como se encontra comumente no ensino do Francês, mas, sobretudo, características contextuais e discursivas, igualmente importantes para a produção textual acadêmica.

5.4.2 Cursos de formação de professores da rede regular de ensino

No caso do Inglês, o Laboratório participa ativamente dos encontros USP-Escola, promovidos pela Pró-Reitoria de Cultura e Extensão da Universidade de São Paulo. Em cursos de 40 horas, buscamos aperfeiçoar a escrita dos professores em inglês e português em diversos gêneros textuais, levando-os a refletir sobre sua própria relação com a escrita de forma geral e compreendendo conceitos como gênero textual, discurso e ensino, avaliação da escrita. Nesses cursos, mostramos como é possível ensinar a escrita em inglês, por meio de gêneros textuais, na escola pública.

Os cursos já oferecidos são os seguintes: O ensino da escrita em inglês através de gêneros textuais; Promovendo a escrita em inglês por meio da mídia eletrônica: wikis; Material didático em inglês: foco no ensino da escrita; O Ensino da Escrita Criativa Fanficcional em Inglês: História, Técnicas e Desafios.

Esses cursos são desenvolvidos pela equipe do Laboratório e com coordenação geral da primeira autora deste artigo. Apesar de não tratarmos especificamente do texto acadêmico nesses cursos, acreditamos que os temas tratados podem auxiliar a formação do professor de línguas materna e estrangeira para promover o letramento e que auxiliará o letramento posterior na universidade.

Nesses cursos, nota-se que o professor, tanto de inglês quanto de português, possui uma relação conturbada com a escrita: de temor ou de incapacidade, por exemplo. Além disso, ele escreve pouco ou nada nessas línguas, o que evidencia um problema na formação desses profissionais. Como ensinar a escrever se ele não o pratica? Se não gosta? Se não vê relevância no escrever? Essas questões são discutidas em nossos cursos.

\subsection{Espaço de estudos e reflexão sobre o letra- mento}

O Laboratório abriga dois grupos de pesquisa registrados no Diretório de Grupos de Pesquisa do CNPq : LEVYG (Língua estrangeira e Vygotsky) ${ }^{10}$ e ALTER - $\mathrm{AGE}^{11}$ e atualmente possui dois projetos de pesquisa com instituições estrangeiras. No grupo de pesquisa LEVYG, que trata do ensino-aprendizagem da língua estrangeira sob uma ótica vygotskiana, encontra-se o sub-grupo sobre o letramento acadêmico. Nesse grupo, buscamos estudar o fenômeno sob essa perspectiva teórica, reconhecendo e procurando interagir com outras correntes teóricas.

$\mathrm{Na}$ área de inglês, desenvolvemos, com a Universidade de Bath, o projeto "O papel do feedback escrito no desenvolvimento de consciência linguística: um estudo de cursos de Inglês para Fins Acadêmicos em duas universidades". O projeto investiga dois aspectos importantes do letramento acadêmico em contexto de internacionalização: a consciência linguística dos alunos e o fornecimento de feedback. A coleta de dados envolve entrevistas com professores e alunos de cursos de escrita acadêmica oferecidos à comunidade USP e de Bath e análise de feedback em atividades escritas realizadas pelos professores.

$\mathrm{Na}$ área do francês, temos um projeto de pesquisa em andamento, com três universidades brasileiras (USP, UNESP, USF) e uma canadense, a Université de Sherbrooke. O projeto foi lançado em 2014, com o título "O desenvolvimento de competências em letramento acadêmico, uma chave do sucesso universitário"12 e financiamento do Ministério das Relações Internacionais do Québec. Em 2015, o projeto foi ampliado (título : La rédaction de genres universitaires : analyse de données et pistes d'action) e recebeu financiamento da AUF (Agence universitaire de la Francophonie). A primeira etapa consistiu na aplicação de um questionário para conhecer as representações e as práticas declaradas de escrita dos alunos da graduação em francês. As etapas atuais são a elaboração de material didático para o ensino de gêneros textuais que causam maior dificuldade aos alunos, material este que é testado no curso de extensão que apresentamos acima. 
Faz-se importante destacar que o Laboratório, por acreditar que problemas complexos exigem uma visão multifacetada, adota uma postura transdisciplinar que privilegia o diálogo e a cooperação de múltiplas perspectivas teóricas. A área de inglês utiliza frequentemente a perspectiva de inglês para fins acadêmicos (SWALES, 2004) para a análise de gêneros textuais, a retórica intercultural (CONNOR, 2004), Academic Literacies (LILLIS; CURRY, 2010) e a pedagogia de V. V. Davydov (ensino desenvolvimental) baseada em pressupostos vygotskianos (FERREIRA, 2015).

O Francês apoia-se nos estudos do Interacionismo Sociodiscursivo (BRONCKART, 1999, 2006, 2008), também embasado em pressupostos vygotskianos, e em seus desdobramentos para o estudo dos gêneros textuais e seu ensino (SCHNEUWLY, DOLZ, 2004; MACHADO, 2010; LOUSADA, 2010; CRISTOVÃO, 2010; BUENO; COSTA HÜBES, 2015), além de trabalhos específicos sobre o letramento acadêmico (MACHADO, LOUSADA, ABREU-TARDELLI, 2004，2005，2007; MOTTA-ROTH, HENDGES, 2010), entre outros. Entretanto, isso não quer dizer que possuímos uma visão limitada a essas perspectivas. O objetivo do centro é compreender o fenômeno do letramento em seus diversos aspectos e pelas mais diversas perspectivas. Nesse sentido, somos um grupo aberto à colaboração.

As reuniões do Inglês ocorrem quinzenalmente e contam com a participação de pós-graduandos, graduandos envolvidos em iniciação científica ou projetos de extensão e interessados da comunidade em geral. Textos teóricos, metodologia de coleta de dados, análise de dados são alguns dos temas em foco nessas reuniões. Os seguintes temas já foram ou são foco de estudo da área de inglês do Laboratório: plágio em seus diversos aspectos, dificuldades de pós-graduandos com a escrita acadêmica em inglês, gêneros textuais e ensino da escrita em instituições no Brasil e no exterior. Destacamos duas pesquisas em andamento: Preparação para mobilidade internacional: Sequências didáticas on-line para a utilização de gêneros acadêmicos em Inglês e Dificuldades com a Escrita Acadêmica em Inglês na Pós-Graduação: Percepções de Alunos.

$\mathrm{Na}$ área de francês, as reuniões ocorrem, em geral, duas vezes por mês e contam com a participação dos membros do Grupo ALTER-AGE. São discutidos textos teóricos, metodologia de coleta e análise de dados e apresentadas pesquisas relacionadas com o projeto do Laboratório. Atualmente, há três pesquisas ligadas ao Laboratório:

- recentemente defendida: Dissertação de mestrado intitulada "A linguagem revelando o desenvolvimento do pesquisador na prática da Iniciação Científica", cujo foco é a escrita e seu papel no desenvolvimento de alunos de Iniciação Científica.

- em andamento: Dissertação de mestrado intitulada "Résumé e Note de lecture: trabalhando com gêneros acadêmicos na universidade", cujo foco são os gêneros textuais resumo e resenha, em francês. A dissertação é o resultado do curso de extensão mencionado anteriormente sobre a escrita desses gêneros acadêmicos.

- em andamento: Dissertação de mestrado intitulada "Desenvolvimento da escrita acadêmica em francês: ensino da produção do gênero textual artigo científico da área de estudos literários", cujo foco é a parceria, também já mencionada, do Laboratório com uma disciplina de Literatura na produção do gênero textual artigo científico.

Diante do exposto, concluímos que o Laboratório de Letramento Acadêmico é, portanto, um local no qual pesquisas são desenvolvidas e isso o diferencia da visão utilitarista dos Writing Centers que existem nas universidades do exterior. As publicações em preparação também o diferenciam de seus similares em outros países. Antes de apresentar nossas conclusões, apontaremos nossos planos futuros e alguns desafios que enfrentamos.

\section{Planos futuros}

Para consolidar o espaço do Laboratório, pretendemos desenvolver as seguintes ações: a) intensificar a oferta de oficinas e palestras, b) ministrar novamente o curso de extensão universitária sobre gêneros acadêmi- 
cos em francês, c) ampliar nossa ação de consultoria nos vários institutos da USP, d) atuar mais proximamente aos gestores das instituições para promoção do letramento acadêmico dentro da USP e em seus diversos campi, e) formar profissionais para o ensino do letramento acadêmico em francês, inglês e português, $\mathrm{f}$ ) propor subsídios teórico-práticos para a institucionalização do letramento acadêmico nas universidades brasileiras por meio da criação de políticas de sua promoção.

Deve-se listar, também, os temas de pesquisa que consideramos urgentes serem abordados pelo Laboratório. Um deles é o uso das tecnologias digitais para a escrita acadêmica. Foco de um dos projetos internacionais dos quais o Laboratório participa, o tema da tecnologia incide sobre a maneira de escrever, de corrigir, de planificar o texto, além de tocar na questão do plágio. Portanto, tal como apresentado nos objetivos de um dos projetos nos quais o Laboratório de Letramento está envolvido, visamos estudar mais a fundo o papel das tecnologias na escrita acadêmica, pensando em como elas podem contribuir para o ensino e como elas podem auxiliar no processo de escrita.

Outro tema que precisa ser melhor explorado é a concepção de escrita (inclusive a acadêmica) e seu papel na sociedade brasileira e na comunidade acadêmica do país. O Laboratório enfrenta desafios para sua maior inserção na comunidade onde atuamos, exatamente por representar um novo artefato cultural para a nossa comunidade, ainda arraigada a crenças e práticas sobre a escrita que precisam ser revistas.

Além disso, uma comparação intercultural sobre certos conceitos são necessários. O plágio constitui-se num exemplo bastante ilustrativo. As concepções anglófona e brasileira, a definição do termo, o enfrentamento da questão pelas instituições, o ensino de como evitá-lo ou não são alguns dos temas que se impõem em tempos de maior exigência de publicação internacional. $^{13}$

\section{Desafios}

Em suas ações para a valoração do letramento acadêmico e para o desenvolvimento do conhecimento acadêmico e de seu ensino, o Laboratório encontra alguns desafios. O primeiro deles, advindo da pouca intimidade do Brasil com a abordagem processual de ensino da escrita, apresenta dificuldades em entender o que seja uma tutoria de um texto escrito. É comum as pessoas acharem que oferecemos serviços de tradução ou revisão, que implicam a delegação do escrever ou revisar a um terceiro. Além disso, os alunos (e não raro professores) frequentemente associam essa tutoria a um serviço exclusivo de apoio a alunos com dificuldades de escrita ou com o idioma estrangeiro, ou seja, um serviço a "deficientes na língua ou na habilidade". Isso mostra que é preciso entender que a escrita é sim um processo colaborativo e que é normal se discutir o texto em andamento com uma terceira pessoa, não importando o quanto o aluno é proficiente na língua ou não e se sua escrita é 'boa'. Parece haver, ainda, a crença de que o texto é algo pessoal, apesar de ter que ser publicado, e que compartilhá-lo é incômodo. Temos enfrentado esse desafio por meio do treinamento dos tutores e da aproximação do Laboratório com os diversos departamentos da USP.

O segundo desafio se refere à valoração do letramento: o que significa para o Brasil escrever e escrever na academia. Nesse sentido, a internacionalização muito contribui para revelar nossos problemas de educação, pois, além de mostrar as deficiências do ensino -aprendizagem da língua estrangeira, amplamente divulgadas pela mídia devido ao programa Ciências Sem Fronteiras, revela também as deficiências de ensino do letramento na escola regular e na academia. Não existe ciência sem sua publicação (sem o ato de escrever); portanto, nossa comunidade acadêmica precisa reconhecer isso e promovê-la. Cremos que algumas ações do Laboratório listadas anteriormente têm buscado enfrentar esse desafio.

Entretanto, o desafio maior é a própria proposta do Laboratório: ela representa uma mudança cultural no ensino do letramento e de sua valoração. Estamos tentando auxiliar o Brasil a fazer as pazes com a escrita (e a leitura) e, diríamos, até conhecê-la e se apaixonar por ela. Como apontamos na seção a seguir, é para esse objetivo maior que se voltam nossas ações e desafios. 


\section{Conclusão}

Neste artigo, procuramos apresentar uma das iniciativas pioneiras no Brasil de constituição de um Laboratório de Letramento Acadêmico, que tem por objetivo auxiliar alunos de graduação e de pós-graduação a produzir textos em língua estrangeira (inglês e francês) e materna. Dando destaque à produção textual em língua estrangeira, na esteira das iniciativas que promovem a internacionalização das universidades, procuramos mostrar as iniciativas já concretizadas para promover o desenvolvimento de estudantes universitários e pesquisadores no que diz respeito à produção textual oral e escrita na esfera universitária/ acadêmica. Sendo assim, relatamos as parcerias com disciplinas, os cursos de extensão e as tutorias, que têm papel essencial no letramento acadêmico de alunos de graduação e pós-graduação.

Procuramos, também, mostrar como a iniciativa da criação de um Laboratório de Letramento Acadêmico pode contribuir para a formação de alunos e professores, promovendo a integração de diferentes disciplinas. Ao mesmo tempo, pareceu-nos essencial abordar os desafios que tal abordagem impõe, já que se trata de uma iniciativa que não é comum em nossas universidades. Finalmente, parece-nos essencial o apoio a esse tipo de iniciativa em um momento especial da internacionalização das universidades e, sobretudo, da produção da ciência em uma perspectiva plurilíngue.

\section{Notes}

1. Tradução nossa para "la centralité du discours, qui sert non seulement à transmettre les savoirs, mais à les elaborer."

2. Centro de escrita.

3. Esta iniciativa é da Unicamp. http://www.cgu.unicamp. br/espaco_da_escrita

4. Foge do escopo deste artigo a discussão do papel da tradução no desenvolvimento do letramento acadêmico, mas nota-se que se constitui numa estratégia recorrente e de caráter emergencial e protelatório adotada pela comunidade acadêmica brasileira. O pesquisador brasileiro ganharia ao aprender a escrever em língua materna e na(s) língua(s) estrangeira(s) requerida(s) por sua área de pesquisa.
5. http://letramentoacademico.fflch.usp.br/

6. http://w3.ufsm.br/labler/

7. Tradução nossa para "A class of communicative events, the members of which share some set of communicative purposes".

8. Até o presente momento, o Inglês e o Francês participam desse projeto.

9. Curso online aberto e massivo.

10. dgp.cnpq.br/dgp/espelhogrupo/4012969521480254

11. http://dgp.cnpq.br/dgp/espelhogrupo/401296952148025

12. Le développement des compétences en littéracie académique, une clé de la réussite universitaire.

13. Esse tema tem sido investigado no projeto Uma investigação preliminar sobre o plágio: a concepção da USP e nos manuais de redação.

\section{Referências bibliográficas}

BAKHTIN, M. Estética da criação verbal. São Paulo: Martins Fontes, 1997.

BALOCCO, A. E. A perspectiva discursivo-semiótica de Gunther Kress: ogênero como recurso representacional. In: MEURER, J. L.; BONINI, A.; MOTTA-ROTH, D. Gêneros: teorias, métodos, debates. São Paulo: Parábola editorial, 2005.

BAZERMAN, C. et al. Reference guide to writing across the curriculum, West Lafayette: Parlor Press, 2005.

BORDIEU, P. The forms of capital (1986). In I.Szeman; T. Kaposy (orgs). Cultural theory: an anthology. Chichester: Wiley, 2011. p. 81-93.

BRANDT, D. Reading, writing, and wealth in the new economy. A lecture presented by the Center for Interdisciplinary Studies of Writing and the Literacy \& Rhetorical Studies Minor. Speaker Series no. 21. Center for Interdisciplinary Studies of Writing, University of Minnesota, 2002.

BRONCKART, J.-P. Atividade de linguagem, textos e discursos: por um interacionismo sociodiscursivo. São Paulo, EDUC, 1999.

BUENO, L.; COSTA HÜBES, T.(orgs). Gêneros orais no ensino. Campinas: Mercado de Letras, 2015.

CANAGARAJAH, A. S. A Geopolitics of Academic Writing. Pittsburgh: University of Pittsburgh Press, 2002.

CARLINO, P. Alfabetización académica diez años después. Revista Mexicana de Investigación Educativa, v. 18, n. 57, pp. 355-381, 2013.

CASANAVE, C. P. Local interactions: constructing contexts for composing in a graduate sociology 
program. In. D. Belcher; G. Braine (eds). Academic writing in a second language: essays on research and pedagogy. Norwood, NJ: Ablex, 1995, 83-110.

CONNOR, U. Introduction. Journal of English for Academic Purposes, v. 3, n. 4, p. 271-276, 2004.

CRISTOVÃO, V. L. L. A quarta-capa no ensino do inglês. In: DIONÍSIO, A. P.; MACHADO, A. R. E BEZERRA, M. A. (orgs.). Gêneros textuais e ensino. São Paulo: Parábola editorial, 2010.

CHARLES, M., PECORARI, D.; HUSNTON,S.(orgs). Academic writing: at the interface of corpus and discourse. London: Continuum, 2009.

FERREIRA, M. M. O livro didático importado de inglês e o ensino da escrita. Trabalhos em Linguística Aplicada , v. 50, 75-95, 2011.

A promoção do letramento acadêmico em inglês por meio do ensino desenvolvimental: contribuições da teoria histórico-cultural. Tese de Livre- Docência, FFLCH, USP, Dez 2015. 179p.

FERREIRA, M.M.; RIOS, V. C.S. (orgs). Redação Acadêmica: múltiplos olhares para o ensino da escrita acadêmica em português e línguas estrangeiras. (em preparação).

FREEDMAN, A.; MEDWAY, P. (ed.). Genre in the new rhetoric. London: TAYLOR \& FRANCIS, 1994.

GAJO, L. Le plurilinguisme dans et pour la science : enjeux d'une politique linguistique à l'université. Synergies Europe ${ }^{\circ} 8,97-109,2013$.

HYLAND, K. Specificity revisited: how far should we go? English for Specific Purposes v. 21, 385-395, 2002.

. Academic discourse: English in a global context. London: Continuum, 2009.

HEWINGS, M. Introduction. In: HEWINGS, M. (eds). Academic writing in context. Birmingham. The University of Birmingham Press, 2001. 9-16.

JUZWIK, M.M. et al. Writing into $21^{\text {st }}$ century: an overview of research on writing, 1999 to 2004 . Written Communication, 23 (.4), 451-476, 2006.

LILLIS, T.; CURRY, M. J. Academic Writing in a global context. London: Routledge, 2010.

LEA, M. R.; STREET, B.V. Student writing in higher education: an academic literacies approach. In: Studies in Higher Education, v.23, 157-172, 1998.

LOUSADA, E. G. Elaboração de material didático para o ensino de francês. In: DIONÍSIO, A. P. ; MACHADO, A. R.; BEZERRA, M. A. (orgs) Gêneros textuais e ensino. São Paulo: Parábola Editora, 2010, p. 73-86.

LOUSADA, E. G.; GUIMARÃES-SANTOS, L. O ensino da escrita acadêmica em francês como segunda língua: um projeto piloto no Canadá. In: FERREIRA, M.M.; RIOS, V. C.S. (orgs). Redação Acadêmica: múltiplos olhares para o ensino da escrita acadêmica em português e línguas estrangeiras. (em preparação).

MACHADO, A. R. "Revisitando o conceito de resumos", in: Dionísio, A. P.; Machado, A. R. E Bezerra, M. A. (orgs.). Gêneros textuais e ensino. São Paulo: Parábola editorial, 2010, p. 138-150.

Resumo. Coleção Leitura e Produção de textos técnicos e acadêmicos. São Paulo: Parábola Editorial, $2004 a$.

Resenha. Coleção Leitura e Produção de textos técnicos e acadêmicos. São Paulo: Parábola Editorial, 2004b.

Planejar gêneros acadêmicos. Coleção Leitura e Produção de textos técnicos e acadêmicos. São Paulo: Parábola Editorial, 2005.

MAN, J.P., et al. Why do some countries publish more than others? An international comparison of research funding, English proficiency and publication output in highly ranked general medical journals. European Journal of Epidemiology v.19, 811-817, 2004.

MILLER, C. Genre as social action. Quaterly Journal of Speech, v. 70, 151-167, 1984.

MOROSINI, M. C. Internacionalização na produção de conhecimento em IES brasileiras: cooperação internacional tradicional e cooperação internacional horizontal. Educação em Revista v.27 , n.01, 93-112, 2011.

MOTTA-ROTH, D. The role of contexto in academic text production and writing pedasgogy. In Bazerman, C.; Bonini,A.; Figueiredo, D. (eds). Genre in a changing world. West Lafayette: Parlor Press, 2009. 317-336.

MOTTA-ROTH, D.; HENDGES, G. R. (2010). Produção textual na universidade. São Paulo: Parábola, 2015.

ROCCO,T.S.;JANUSKA,C.M.;GIONTI,L.A.N.;MUNN,S. L.U. Creating a support structure for academic writing and publication support: the rationale and lessons learned. In Wang,V.C.X. (ed). Handbook of Research on Scholarly Publishing and Research Methods. Hershey, Pa: IGI Global. 2015.

RUSSELL, D. Writing in the academic disciplines. $A$ curricular history, 2a ed., Carbondale y Edwardsville: Southern Illinois University Press, 2002.

SALAGER-MEYER, F. Scientific publishing in developing countries: challenges for the future. Journal of English for Academic Purposes v.7, n.2, 121-132, 2008.

SCHNEUWLY, B.; DOLZ, J. Gêneros orais e escritos na escola. Campinas: Mercado de Letras, 2004. 
138 Marília Mendes Ferreira e Eliane Gouvêa Lousada, Ações do Laboratório de Letramento Acadêmico...

SILVA, E.; LOUSADA, E. G. O plano de estudos: um gênero textual acadêmico para pleitear intercâmbio. Horizontes, v. 32, n. 2, p. 73-87, jan./jun, 2014.

STREET, B. Literacy in theory and in practice. Cambridge: Cambridge University Press, 1984.

SWALES, J. M. Genre analysis. Cambridge: Cambridge University Press, 1990.

Research Genres. Cambridge: Cambridge University Press, 2004.

SWALES, J. M.; FEAK, C. B. Academic writing for graduate students. Ann Arbor: The University of Michigan Press, 2004.

UZUNER, S. Multilingual scholars' participation in core/ global academic communities: a literature review. Journal of English for Academic Purposes, 7, 250263, 2008.

VASCONCELOS, S.M.R.;. SORENSON, M.M.; LETA, J. Scientist-friendly policies for non-native English speaking authors; timely and welcome. Brazilian Journal of Medical and Biological Research, 40, 743747, 2007.

VYGOTSKY,L.S. The collected works of L.S.Vygotsky. Volume 4. R. W. Reiber (org). New York: Plenum, 1997.

WARSCHAUER, M. The changing global economy and the future of English Teaching. Tesol Quaterly 34,3, 511-535, 2000.

Recebido em: 29/02/2016 Aceito em: 219/05/2016 


\section{Laboratório de Letramento Acadêmico}

\section{Ficha de Atendimento}

Nome:

Telefone de contato para confirmaçãodo agendamento:

Dia e hora do atendimento:

Departamento:

Unidade/Instituto:

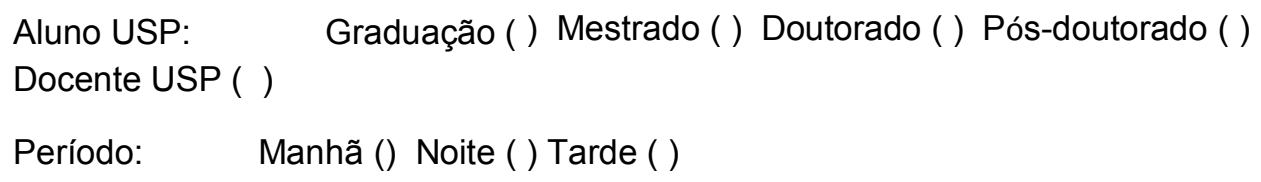

Texto discutido no atendimento:

Motivo para escrita do texto:

Disciplina/área a qual pertence o texto:

Coautoria: $\operatorname{SIM}($ ) NÃO( )

Coautor(es):

Aspectos discutidos no texto (a ser preenchido pelo monitor durante o atendimento): 


\section{Laboratório de Letramento Acadêmico}

\section{Ficha de Feedback do Atendimento}

Sua opinião sobre o trabalho que desenvolvemos no Laboratório é de grande valia para que possamos avaliar nossos métodos e aprimorar as sessões de discussão de seu texto. Agradecemos por sua colaboração!

Por gentileza, queira expressar sua opinião sobre o atendimento que você recebeu:

Sugestões (como poderíamos aperfeiçoar os atendimentos presenciais): 